\title{
A Missão Paz e imigração haitiana em São Paulo: 2010-2015
}

\author{
Entrevista com o Padre Paolo Parise
}

\section{Por Kassoum DIÉMÉ*}

Esta entrevista tem o objetivo de fazer um diagnóstico da situação do acolhimento a imigrantes haitianos na cidade de São Paulo. A fala do Padre Paolo Parise, Coordenador do Centro de Estudos Migratórios - CEM da Missão Paz e envolvido no trabalho com imigrantes há pelo menos três décadas, é fundamental para alcançar o nosso propósito. A Missão Paz é uma referência no acolhimento a imigrantes nesta cidade. Perguntamos ao Pe. Paolo Parise sobre a história de atendimento e acolhimento oferecidos pela Missão Paz, bem como sobre sua estrutura. $\mathrm{O}$ seu relato revela mudanças do perfil dos grupos atendidos e das condições elegíveis com o passar do tempo. Mudanças estão ainda ocorrendo no processo migratório. A chegada de haitianos e sua procura pelos serviços oferecidos pela Missão Paz a partir de 2010 provocou novas e significativas mudanças. Como bem destacado pelo entrevistado, o acolhimento oferecido pela Missão Paz a haitianos considerou dimensões como: gênero, trabalho, idioma, família, economia, saúde, cultura, profissionalização, bem como necessidades jurídicas. Apesar deste olhar abrangente sobre acolhimento, baseado na concepção religiosa e com uma perspectiva ecumênica, a Missão tem seus desafios. Neste processo de acolhimento ocorreram parcerias e colaborações tanto por parte de outras instituições como da sociedade paulistana.

\section{Padre Paolo Parise, gostaria de saber quando e como você começou a trabalhar com a questão dos imigrantes.}

Pe. Parise: Prazer poder conversar com você. Eu diria que comecei já na Itália, com os migrantes, porque na hora que entrei numa congregação religiosa chamada Scalabrinianos, que é aquela a que pertenço atualmente, eu já sabia que ia trabalhar com imigrantes e refugiados. Então, desde o início, tive experiência no mundo da migração, na parte sul da Itália, na Pulha, um pouquinho na Calábria onde - de maneira especial - na Pulha vinham imigrantes do norte da África para colheita de azeitonas, para colheita de tomate, colheita de uva. Depois, também em Roma, trabalhei com a comunidade brasileira e latino-americana, então imigrantes que vieram para lá, e no norte da Itália também um pouquinho e algumas experiências pontuais na Suíça e na Alemanha. E depois, aqui no Brasil. Na Missão Paz, desde 2010, tive essa experiência de estar nesse lugar, que é um lugar realmente de muita imigração e contato com refugiados.

${ }^{*}$ Mestre em Sociologia na UNICAMP. Realizou esta entrevista em 18 de novembro de 2015 no Centro de Estudos Migratórios da Missão Paz em São Paulo. 
Em relação à Missão Paz, esta unidade neste bairro ${ }^{1}$ foi construída quando?

Pe. Parise: Então, é interessante que ela começa a surgir em 1930, como Paróquia Nossa Senhora da Paz e em 2012 terá o nome Missão Paz. Então, ela existe desde os anos 30, com uma estrutura de madeira, e no ano de 1939 começou a estrutura em alvenaria, esta estrutura atual. Em 1939, num primeiro momento, começou atendendo coreanos, vietnamitas, latino-americanos, africanos, italianos. Então foi, vamos dizer, respondendo aos vários fluxos migratórios novos.

\section{Esse atendimento inicial então era reservado aos italianos? A abertura do atendimento para outras nacionalidades começou mais ou menos em que época?}

Pe. Parise: Eu diria que foi progressiva. Não lembro exatamente as datas. Mas, por exemplo, em 1965 foi quando começou ser atendida a comunidade coreana. E podemos dizer então que à partir dos anos 1960 começa uma abertura sempre maior, seja em nível de coreanos e vietnamitas, seja daqueles que fugiam de ditaduras na américa latina nos anos 1970. Então foi se abrindo sempre mais. Podemos dizer que os anos 1960, ocorre a grande mudança com italianos. Porque também a imigração italiana começa a diminuir naquela época.

A Missão Paz é composta pelo Centro Pastoral do Migrante e pelo Centro de Estudos Migratórios e também pela Casa do Migrante. Em poucas palavras, 0 que é a Pastoral do Migrante e o que é a Casa do Migrante? Qual é a história dessas duas unidades que compõem a Missão Paz?

Pe. Parise: A Casa do Migrante é interessante porque lá nos anos 1970, ela começa atendendo imigrantes internos. Ainda em uma fase que vinham muitos do nordeste para São Paulo e eles precisavam de acolhida. E aqui embaixo do viaduto existia uma rodoviária onde chegavam os ônibus com o pessoal do nordeste. Posteriormente, a partir do final dos anos 1980 já começou a mudar o rosto e precisava-se acolher imigrantes e refugiados. Então, por isso ela foi evoluindo da migração interna para imigração internacional e refugiados. $E$ atualmente ela tem uma série de serviços. Há 110 vagas para pessoas dormirem, se alimentarem, atendimento psicológico, atendimento através da brinquedoteca para as crianças, lugar para lavar as roupas. Tem todos esses serviços. Por outro lado, o Centro Pastoral do Migrante começa, lá pelos anos 1980, a funcionar e os serviços vão se ampliando. Eu diria que a partir de 2010 começa a se ampliar ainda muito mais os serviços. No início, o que era parte, os primeiros serviços, documentação e atendimento jurídico, que continuam até hoje - e ainda foram potencializados, porque $o$ atendimento jurídico tem duas advogadas e não mais uma. E pela documentação, para se ter uma ideia, passam cinco mil pessoas por ano, só para documentação. Mas além deste serviço, há também outro. Tem a parte não só da documentação e de atividade jurídica, pois com a chegada dos haitianos surgiu o Eixo Trabalho que, claro, está disponível para todos os imigrantes. Mas fomos provocados, ou seja, as empresas vêm aqui e passam por um treinamento e depois elas contratam. E os imigrantes também passam 
por um momento de treinamento, de formação para saber quais são os seus direitos, para saber como denunciar trabalho degradante, etc. Então isso foi uma ampliação que surgiu quatro anos atrás. Mas tem também outra parte, que é todo atendimento de saúde. Temos seis médicos voluntários nesse momento; encaminhamos, acompanhamos. Tem uma parte de atendimento psicológico, tem uma parte ainda de educação onde acompanhamos as crianças que têm que ir para a creche e para escola; e tem uma parte que nós chamamos "família e comunidade" que é uma equipe que visita as famílias, de maneira especial nas ocupações, para ajuda-las, para ver se elas têm alguma necessidade especial. Então, são cinco grandes eixos: saúde, educação, jurídico e documentação, trabalho, família e comunidade. Além disso, o Centro de Estudos não nasceu aqui na Missão Paz. Nasceu no Ipiranga ${ }^{2}$ e nos anos 1990 veio para cá, para a Missão Paz. Eu acho que aqui é o melhor lugar para o Centro. Tem uma biblioteca especializada, tem uma revista [Revista Travessia], faz assessorias, tem o grupo de estudos. Ontem mesmo tinha aqui um grupo de estudo da USP e da PUC. Além disso, claro, eu acho que temos que lembrar também de dois outros serviços transversais que são a web rádio, que surgiu há dois anos, e tem programas ao vivo também na Rádio 9 de julho. E tem outra questão que é a incidência política, ou seja, há pessoas que participam de reuniões de nível municipal, estadual e federal para melhorar seja as políticas, seja as leis migratórias. Nesse momento, por exemplo, estamos acompanhando o projeto de lei $2516 / 2015^{3}$ que está sendo conversado na câmara.

\section{Gostaria de saber de quando são os primeiros registros de atendimento às mulheres imigrantes pela Missão Paz?}

Pe. Parise: Você diz as mulheres em geral? Teria que checar no sistema. Mas com certeza nos anos 1980. Ou talvez, ainda mais para trás, em 1965, quando chegaram coreanas. Agora se você pegar os italianos, então já há registros dos anos 1930, as italianas. Eu acho que a presença das mulheres sempre foi acompanhada desde o início. Só que mudou o rosto. As vezes são italianas, as vezes são coreanas, vietnamitas, são chilenas, depois numa fase, bolivianas. Vai mudando o rosto. Considerando a cronologia histórica, as primeiras foram as mulheres italianas.

\section{Considerando os últimos cinco anos, a grande maioria das mulheres que estão sendo recebidas e atendidas pela Missão Paz seria de qual nacionalidade?}

Pe. Parise: Então, eu diria, por exemplo, que o caso da Bolívia é interessante porque há muitas mulheres. Se calcula em São Paulo, aqui temos $51 \%$ são homens e $49 \%$ são mulheres. Então podemos dizer que é uma grande presença feminina. Você faz a média, são mais ou menos 150.000 bolivianas. No caso do Peru, também se calculam 18.000, e há muitas mulheres nessa imigração. 0 caso do Paraguai, em São Paulo se calculam 40.000, e também aqui, são muitas mulheres. Então eu diria que a Bolívia, o Peru e o Paraguai são um grupo da América latina com muitas mulheres. Se nós olharmos agora para a parte da 
África, claro, a proporção é muito maior de homens. Mas há mulheres nos últimos cinco anos que vieram especialmente de Angola, do Congo, que eu vejo. Por exemplo, domingo passado, do Senegal, no salão, de trezentos homens, havia dez mulheres. Mas eu diria da África, minha percepção, por exemplo, é que para Angola e Congo, há grande presença de mulheres. Do Haiti, nos últimos cinco anos, eu diria que a presença de mulheres foi de $10 \%$ até mais ou menos o ano passado. Aumentou muito. Agora estamos falando de $20 \%$ de presença de mulheres porque os homens que encontraram trabalho fizeram, no último ano, chegar a esposa. Então por isso aumentou a presença. Se não, sempre beirou entre 8 e $10 \%$ a presença de mulheres haitianas.

\section{Falando em números, quantos haitianos a Missão Paz acolheu considerando o ano de $\mathbf{2 0 1 0}$ como ano de referência?}

Pe. Parise: Olha, eu posso te falar mas é melhor depois eu te passar por e-mail os números certinhos. Eu lembro que em 2010 foram os primeiros 28 haitianos. E, para ter uma ideia, foi aumentando. Tanto que em 2014 chegaram quase 4.700 haitianos. Isso te dá uma ideia do aumento. Este ano estamos ao redor de 3.000, mas eu puxo do sistema e te passo tudo. Primeiro 80, depois quase 800, 2.300, 4.700. É um aumento realmente muito grande. Nós calculamos mais ou menos 11.000 - não, agora já são quase 12 -, 12.000 haitianos que passaram por aqui de 70.000 que estão no Brasil.

\section{Quanto ao atendimento, no que diz respeito aos haitianos aqui em São Paulo, a Missão Paz começou a atender, a acolher haitianos quando?}

Pe. Parise: Em 2010, começou com 28. Então coincide mesmo depois do terremoto. Agora, interessante que eu diria que os dois momentos mais desafiadores foram 2014 e 2015. Porque, até 2013, nós tínhamos capacidade de acolhê-los. Em 2014 tivemos aquele grande grupo que veio do Acre e tivemos que abrir auditórios, salões... Naquele ano chegamos a loucura! Eu lembro ainda, foi dia 11 de Abril de 2014, uma data que ficou marcada. Gente, chegamos a 350 pessoas por dia. E até, pode ser que depois você pergunte, o grande drama foi que nós até pressionamos muito o Ministério da Justiça e a prefeitura. Nessas datas não tinha, quer dizer, tinha a Missão Paz e um pouco o Arsenal da Esperança ${ }^{4}$. Mas estruturas públicas para acolher não existiam. Então, teremos, em Maio de 2014, a Prefeitura que abre um espaço emergencial por quatro meses mais ou menos, aqui na Rua do Glicério. Depois, quase no final do ano, abre na Bela Vista, com os Franciscanos, faz-se um convênio, repassa o dinheiro e os Franciscanos, o SEFRAS, começa a fazer funcionar esse serviço. Aí faz-se um outro convênio com as Irmãs Palotinas e depois fazem outro convênio com as Irmãs Scalabrinianas, em menos de um mês atrás. Então, atualmente temos três espaços conveniados com a Prefeitura e um espaço gerenciado pelo Estado. Então aumentou. Mas o tempo de resposta, quer dizer, foi muito dramático por meses e meses. Até quatro meses atrás.

\section{Esse espaço que é gerenciado pelo Estado se chama como?}


Pe. Parise: Esse se chama "Terra Nova" e fica perto do outro do SEFRAS. Só que aí existe um problema de Legislação. A legislação do Brasil não permite que o Estado abra espaços para abrigo. Isso é tarefa municipal. Então, de fato, esse é bem específico. É destinado à vítimas de trabalho escravo e tráfico de pessoas. Então, é muito limitado. Muitas vezes eu nem conto esse. Porque chega um haitiano e eu não posso mandar para lá. Por isso, de maneira efetiva, são estes três espaços da Prefeitura.

\section{E esses convênios são sempre feitos com a lgreja Católica?}

Pe. Parise: Sim. Você vê, uma parceria é com Franciscanos, o SEFRAS; outra é com Irmãs Palotinas, a casa da mulher; e outra é com Irmãs Scalabrinianas, que é a última. Então são três convênios.

\section{E já ocorreu da Missão Paz acolher famílias aqui?}

Pe. Parise: Sim. Você diz haitianas?

\section{No geral, mas especificamente haitianas.}

Pe. Parise: Sim, sim. Temos famílias de Angola, temos famílias do Congo, temos às vezes famílias da Bolívia. Temos famílias haitianas, várias famílias. Famílias sim, acontece - Claro que na maioria não chegam famílias - tanto é verdade que estamos pensando em criar um espaço para famílias. $O$ grande problema é que aí a gente esbarra com uma situação de legislação. A estrutura ${ }^{5}$ está tombada como obra de arte. Então, estamos com arquitetos estudando para mexer, mas a Prefeitura não está deixando. No dia em que recebermos autorização, já pensamos em um espaço para construir quitinetes para famílias, para poder acolhê-las.

Quais são os atendimentos que a Missão Paz oferece e o que tem como estrutura para isso? Há diferença no acolhimento das haitianas em relação aos haitianos? Em outras palavras, considerando somente $o$ acolhimento dos haitianos, há formas diferentes de atender homens e mulheres?

Pe. Parise: Em termos numéricos, como comentei antes, os haitianos homens são quase $90 \%$. Isso é uma questão. Em relação às mulheres haitianas, foi sempre mais fácil arrumar vagas para dormir. Do outro lado, para arrumar emprego, fica muito mais difícil. Então, geralmente tem vagas de emprego para homens. Para mulheres tem sempre menos. As mulheres geralmente conseguem trabalhar no mundo dos restaurantes, da hotelaria e são garçonetes em restaurantes etc. Essa é a área maior. E algumas como empregadas domésticas. Mas não é tão fácil, como comentei, arrumar emprego. Outro detalhe no caso das mulheres, é claro, depois tem toda a fase em que elas começam, a fase de ser mãe, de estarem grávidas, e aí tem toda a questão de ajudá-las no processo do pré-natal para que entendam como funciona o serviço de saúde pública no Brasil, a questão de procurar espaços onde elas possam dar à luz e acompanhar depois do parto. São todos desafios bem diferentes. E, eu diria sobre as mulheres, que tivemos 
ainda alguns desafios porque tínhamos mulheres que só falavam crioulo e não francês. Isso complica também porque é mais fácil, óbvio, encontrar pessoas que falem francês do que crioulo. Enquanto os homens, em geral, percebemos que falam bastante francês, necessitamos às vezes de tradutores para atender as mulheres. $E$ depois acho que é um desafio, muitas mulheres que deixaram os filhos no Haiti com os pais. Eu diria que é até uma pressão psicológica que faz com que elas precisem ser atendidas, acompanhadas, porque os filhos ficaram lá. Então é aquela dor, aquele sofrimento porque querem trazê-los, não têm dinheiro. E tivemos outra coisa que, infelizmente é dramática, eu diria, que são as mulheres que vieram via Acre. Tivemos várias que, no Peru, foram estupradas - ou pela polícia, ou por grupos de traficantes humanos, ou coiotes. Elas chegam com esse drama de violência na carne. Também tem isso, infelizmente.

Teria registro de algumas que, além dos setores citados, trabalham no comércio?

Pe. Parise: Sim, tem. Estava esquecendo. Tem uma por exemplo, uma menina que trabalha no Brás, que vende sapatos; tem três lanchonetes aqui na região, com mulheres que fazem comida; há várias mulheres que trabalham colocando tranças, aqui na frente da igreja mesmo.

Você mencionou a questão dos filhos que ficam no Haiti. Isso quer dizer que existe um número expressivo de haitianas que vêm e que já eram casadas?

Pe. Parise: Sim, tem. Olha, tivemos vários casos em que a mulher chegou antes do homem. Eram casadas, então, não veio antes o homem, mas veio a mulher. Temos esse registro sim. E algumas que estão sozinhas com os filhos e que vieram para manter os filhos.

\section{Ou seja, solteiras também?}

Pe. Parise: Sim, têm filhos mas não são casadas.

Quais os motivos mais citados por eles e elas como razão de sua vinda para o Brasil? E o que dizem, em particular, as haitianas à respeito disso?

Pe. Parise: Eu posso dizer o que eu percebo. Depois será interessante você conversar com elas, com eles, nesses dias em que eles esperam muito. Vai ser uma boa oportunidade para você recolher dados. Eu sinto que em geral, os homens, temos uma boa parte que já tinha saído do Haiti e estavam na República Dominicana. Então não é uma primeira migração. Eles estão migrando da República Dominicana para o Brasil. Tivemos um outro grupinho do Equador para o Brasil e um grupo do Haiti para o Brasil. Eles dizem, claro, que a situação lá era muito complicada, mas ao mesmo tempo, ouviram falar que no Brasil se arruma muito fácil um emprego. Coisa que não é real agora. Então, muito fácil arrumar emprego, o salário é bom e que o Brasil acolhe bem. E que o Lula, na época, falou que os haitianos são bem vindos no Brasil. Então, é esse conjunto de fatores. Também diria que as mulheres entram nesse embalo, ouvindo 
falar... Há uma parte pequena de mulheres que vieram e cujos maridos vieram antes, e outras, porque há algumas que me falaram que queriam estudar. E de fato, há algumas que já estão estudando, fazendo medicina, uma está fazendo enfermagem. Conheço as que estão estudando e outras, claro que vieram para ajudar a família, os pais, os filhos. Então, é sempre a questão econômica, eu diria, que é a mais importante. $E$, por outro lado, se escolheu o Brasil também porque foi facilitada a documentação.

\section{A Missão Paz tem informações sobre as vidas desses haitianos e haitianas no seu país de origem? Eles contam um pouco, por exemplo, se trabalhavam lá, que tipo de ocupação tinham, ou quanto ganhavam como salário? Vocês conseguiram ter algumas informações à respeito disso?}

Pe. Parise: Eu diria que a gente respeita muito se eles querem falar ou não. Há casos que eles falam. Há outros que eles ficam muito, quer dizer, conservam para eles. Então, é claro, para alguns fiquei sabendo da quantidade de filhos, do trabalho que faziam. Mas em geral, eu diria que eles guardam muito para eles estes dados. Eu também tento não fazer essas perguntas, não invadir suas privacidades.

\section{Quais seriam as principais demandas dos haitianos aqui em São Paulo? Dos} haitianos que passam pela Missão Paz? E há diferenças entre as demandas dos homens e das mulheres?

Pe. Parise: A Primeira grande demanda é de trabalho, nesse momento. Este momento, claro, eu acredito que é uma coisa progressiva. Por exemplo, neste momento, 2015, o trabalho é uma das questões fundamentais. Enquanto, por exemplo, dois anos atrás, era uma coisa que se arrumava com certa facilidade. Então depende muito. Hoje em dia o trabalho é a grande demanda. A segunda grande demanda é a documentação que, a partir do dia 12, os dois Ministérios ${ }^{6}$ fizeram este acordo e publicaram esta lista de 43.700 haitianos que vão ter a passagem do protocolo para o RNE. Então isso, nesse momento, também é outra grande demanda. Você viu, estão vindo 400 por dia em média. E, por outro lado, nasce a demanda, por exemplo, que a Polícia Federal está com uma lista de espera muito grande, não tem agendamento nesses dias. A gente está preocupado com o tempo que isso vai demorar. $E$, também a outra demanda é que as taxas aumentaram. Então, só de taxas eles vão precisar de 310,00 reais, mais tradução juramentada, ao redor de 80,00 à 100,00 reais. Então eles vão gastar entre 400,00 e 500,00 reais para esta regularização. Outra grande demanda era aula de português. Hoje mesmo tem duas turmas fazendo aula.. Então está tudo nas mãos das instituições, da sociedade civil. Trabalho, documentação, aulas de português e a outra questão é a das casas; aluguéis muito caros. Às vezes, eles se juntam em espaços onde só caberia uma pessoa e moram em quatro, porque tem que dividir o aluguel. Então vejo que estes elementos são importantíssimos nesse momento. A questão de saúde é rara, porque, por exemplo, eles em geral, são pessoas muito saudáveis, jovens. Há aquelas exceções, mas não é tão grande. 
E creche, eu estava esquecendo, para as mulheres, creche. Não tem creche. Conversei também essa semana, tem umas que estão esperando há seis meses; outras, há sete meses, e não sabem quando vão conseguir. Então, enquanto não tem creche, elas não podem trabalhar e se cria um círculo vicioso.

\section{E por que procuram a Missão Paz para serem acolhidos e atendidos?}

Pe. Parise: Eu diria que por vários fatores. Um, porque foi a primeira instituição que abriu as portas quando eles chegaram em São Paulo. Isso já criou uma tradição de mais de cinco anos. Apesar de existir outros lugares hoje em dia, isso é bom, eles ainda confiam muito na Missão Paz. Ontem vieram dois de Santa Catarina. Falei para eles: "Por que vieram? Gastaram dinheiro de..."

Disseram: "Não, aqui nós confiamos!"

Eu lhes disse: "Tá bom, mas gastaram dinheiro e tudo. Podiam fazer lá a documentação, em Chapecó, em outros lugares."

Então, há um elemento de confiança nessa tradição de acolhida, e tem depois o fato do nosso grupo estar deslocado, com outros nomes no Brasil: em Manaus, em Cuiabá, no Rio de Janeiro, aqui em São Paulo, em Santos, em Curitiba, Porto Alegre..., então em uma série de cidades, onde eles já nos conhecem. Por exemplo, em Manaus, passaram 5.000, onde foram acolhidos. Já em Manaus, muitos sabiam que havia uma outra estrutura semelhante aqui. Então eles circulam muito entre essas instituições. Então, às vezes eles chegam e falam "Olha, o Padre Gelmino, de Manaus, o Padre Holmes, de Cuiabá". E eles já nos conhecem. Isso, independentemente de serem católicos ou não. Podem ser evangélicos. Então tem essa estrutura que é bem capilar no Brasil.

Considerando o desafio do acolhimento da Missão Paz, imagino que vocês teriam parceiros. Quais seriam os principais parceiros, se é que existem, nos últimos tempos e que tipo de apoio vocês recebem deles?

Pe. Parise: Eu diria que podemos dividir então em nível econômico. Neste ano, a Missão Paz precisa de mais ou menos 1.600 .000 para se manter. Deste 1.600.000, quase 920.000 vêm da própria Igreja. É dinheiro colocado como em Manaus e outros lugares. Aqui na Missão Paz nós colocamos 920.000 para manter. Então, o restante, nós atualmente temos duas fundações, dois projetos que nos ajudam, mas é sociedade civil. Projetos da Europa que nos ajudam. Então, estão mais ligados à Espanha e a Holanda, que nos ajudam a completar. Agora, em nível de incidência política, temos parceria por exemplo com o Conectas, com o Cáritas, com quem fazemos pressão política juntos, o SEFRAS e outros grupos. Em nível de atuação, por exemplo, na cidade de São Paulo, tem uma estrutura chamada Rede Interinstitucional em Favor dos Imigrantes. São todas as instituições que querem trabalhar com imigrantes, que se juntam uma vez por mês. Então tem realmente uma série de parceiros. Até com as outras casas de acolhida a gente dialoga, com o SEFRAS, com a casa da mulher, com as Irmãs Scalabrinianas. A gente dialoga e tem realmente muitas parcerias. 
E a contribuição ou colaboração do Estado de São Paulo ou da Prefeitura de São Paulo? Tem alguma relevância nessa parceria?

Pe. Parise: Não, não tem nada. Zero. Então podemos dizer que, do ponto de vista econômico, não temos ajuda federal, estadual ou municipal. Tivemos sua colaboração num momento de emergência em que deram marmitex e cobertores. Em um momento, como por exemplo, Janeiro, Fevereiro, Março, Abril, Maio e até quase Junho de 2015. Deram uma ajuda, mas isso, a prefeitura.

E em termos políticos, daria para falar que existe uma parceria ou uma colaboração da Prefeitura? Em outras palavras, politicamente falando, sem o trabalho da Prefeitura, como ficaria o trabalho da Missão Paz?

Pe. Parise: Como posso dizer aqui? Eu diria que são complementares, não alternativos. Nós, com a prefeitura, tivemos um bom diálogo. Isso tem que dizer, nestes dois anos. E, ao mesmo tempo, nós cobramos muito. Eu acho que cobramos a abertura de mais casas, ao mesmo tempo em nível federal e nível municipal, e, do outro lado, eu digo sempre que não foi uma abertura espontânea. Foi porque também teve cobrança. Teve cobrança, o fato estava aí, e precisava de uma resposta. Mas, do outro lado, também encontramos pessoas, seja a nível federal, no Ministério do Trabalho, Paulo Sérgio de Almeida, seja no Ministério da Justiça, seja em nível de Prefeitura, pessoas que dialogaram bastante.

Voltando de novo para o caso do acolhimento dos haitianos, nos processos de recrutamento de trabalhadores haitianos e haitianas especificamente - mas isso pode se estender a outros imigrantes aqui na Missão Paz, qual é o lugar reservado para a mulher haitiana? Ela tem um espaço dentro dessas empresas, dentro da mão de obra procurada por essas empresas? Dito de outro modo, as empresas, no processo de recrutamento, já chegam com alguma porcentagem ou determinados tipos de trabalhos reservados para mulheres?

Pe. Parise: Tem, tem. Elas não colocam claro, "mulher haitiana", porque pode ser mulher congolesa, por exemplo. Então, as empresas, na terça e quinta, recebem um treinamento e sensibilização, e depois na parte da tarde, elas penduram uma folha onde está escrito o número discriminado, homem ou mulher. Às vezes, por exemplo, duas mulheres, e coloca folha de pagamento, quanto vão receber, benefícios, se tem moradia, se tem ajuda de todo tipo e a localização. Vendo isso pendurado, as mulheres, neste caso, se colocam na frente e aparecem nas entrevistas uma por uma. Há sim, vagas para mulheres.

Tentando focar sobre os haitianos, e por meio do recrutamento dessas empresas, qual é a faixa salarial média?

Pe. Parise: Eu diria que a grande faixa está ao redor de 900,00 reais. Nós sempre tentamos puxar para chegar a $1.000,00$, claro que chega a $1.000,00$, $1.100,00$. Mas a faixa normalmente, dizemos, a mais comum é entre 900,00 e $1.000,00$ reais. 


\section{Como a Missão Paz avalia a política de acolhimento de haitianos pelo Estado brasileiro?}

Pe. Parise: Eu acho que teve uma progressão, uma evolução. Eu acho que, por exemplo, quando se decidiu abrir para os haitianos foi um ato, eu acho, humanitário muito interessante. Porém, por outro lado, também eu acho, não podemos ser ingênuos, o Brasil precisava de algum tipo de mão de obra que o brasileiro não queria fazer. Então, é humanitário, mas também tem o interesse de grandes corporações aí. $\mathrm{O}$ outro grande elemento é que se num primeiro momento abriu as portas, falhou muito, porque política migratória não é só dar o visto. Tem que dar casa, tem que se preocupar com mecanismos de inserção, aulas de português e tudo isso. Faltou tudo isso. Então os haitianos começaram a chegar e a estrutura do Estado brasileiro não estava pronta. Apanharam para caramba. E também, várias pessoas no Brasil me disseram que se não fosse a Igreja, teríamos passado vergonha, ou melhor, passamos vergonha porque a Igreja fez o que o teríamos que ter feito. Eu acho isso um dado, de fato. As melhores respostas articuladas começaram este ano. Ou seja, depois de cinco anos. Faltou planejamento, faltou visão de conjunto quando nós pressionamos a questão da carteira de trabalho, pressionamos também a questão das casas de acolhida, pressionamos sobre a rota onde se estavam sendo explorados, extorquidos os imigrantes. Então, realmente foi na base da pressão.

Na sua avaliação quais são os desafios das instituições que estão acolhendo os imigrantes haitianos, particularmente aqui em São Paulo? Qual é o desafio da Missão Paz hoje, nesse acolhimento?

Pe. Parise: 0 desafio é sempre aquele de se manter, o desafio econômico; encontrar os fundos para levar adiante os serviços; o desafio de dar respostas rápidas. Ou seja, não somos como o Estado que dá respostas muito demoradas. Tem que dar respostas rápidas. Por exemplo, foi publicada a lista no dia 12, no dia 13 a gente já estava com pessoas treinadas para dar uma resposta para todos esses haitianos que estão vindo para cá. Então, temos que ser rápidos, temos que ter estrutura muito dinâmica, ágil. Isso é difícil, como para toda estrutura a tendência é se fossilizar, se acostumar, e a imigração leva sempre ao movimento. Então acho que uma estrutura como a Missão Paz tem este grande desafio. E depois, trabalharmos em dois níveis, e não ficar só em um. Não ficar só no local, trabalhando também no geral, em nível nacional de incidência política, e não ficar só na incidência política e trabalhar também a nível local. Acho que esta duplicidade de ação, eu vejo como grande desafio. Porque às vezes, por exemplo, trabalhar em nível federal é gasto de passagem, dentre outras coisas e, às vezes, os resultados parecem demorados. Mas é algo fundamental. No caso do Projeto de Lei 2516/2015, conseguimos, nós estamos mandando pessoas, digo não toda semana, mas quase a cada duas semanas para conversar com os deputados dos diferentes partidos, "passar a cola", dizer que tem que melhorar aqui. Então é um trabalho de formiga "invisível", parece dinheiro jogado fora, mas é o segredo para melhorar a política. 
Quais são os ramos de atividades dessas empresas que contratam haitianos? Em que setores a maioria dessas empresas que recrutam, que contratam haitianos, atuam?

Pe. Parise: Tivemos os homens que atuaram quase $50 \%$ na construção civil. Mas agora, neste ano tá abaixo de $4 \%$ por causa da crise da construção civil. Então homens em geral, na construção civil era muito forte. Depois, nos frigoríficos no sul, para trabalhar com carne e frango, que esse é outro grande setor; e atualmente, de serviços gerais. As mulheres também em serviços gerais, restaurantes, hotéis e como babás e domésticas. São esses os setores.

Para a Missão Paz onde começa e onde termina o acolhimento aos imigrantes? Pe. Parise: A gente tenta trabalhar sempre com aquela questão de que o imigrante tem que ser o protagonista, o sujeito, que não pode ser tratado como coitadinho; tem que ser ajudado naquele momento, mas depois caminha com suas próprias pernas. Então, evitar o assistencialismo. Então, eu acho que tem que ver caso por caso. Tem a pessoa que vai precisar de abrigo; outra precisa ser ajudada a encontrar um espaço para alugar, que já tem o seu dinheirinho. Há uma variedade muito grande. Dizer onde começa e onde termina não é tão fácil. Em geral começa com documentação, aula de português e a acolhida. Às vezes termina quando sai da Casa do Migrante, mas continua na aula de português; sai da Casa do Migrante, arrumou emprego e quer fazer um curso profissionalizante. Então uma trajetória de um serviço termina, já começa outra. O ser humano é bem dinâmico.

O que pensa a Missão Paz enquanto instituição religiosa sobre - não falando especificamente do Brasil, mas de um modo geral - as políticas migratórias adotadas pelos Estados que restringem a migração humana?

Pe. Parise: Estamos diante de conjunturas, nas quais, por várias razões, os países tentam se fechar. Atualmente é a questão do terrorismo. $O$ imigrante é visto como uma ameaça; ameaça cultural, ameaça que rouba trabalho, ameaça que traz violência; na fase do ebola, que traz doença. Eu acho que estamos numa conjuntura que não é das melhores. Mas, eu acho que as políticas restritivas em relação a migração não funcionam. Podemos construir todos os mecanismos, tipo os Estados Unidos, para frear a migração e não conseguiremos. Com toda tecnologia, todo o gasto e investimento. Pensamos na Europa, os barcos continuam chegando. Acho que se trata de, primeiro, - a Missão Paz pensa, claro - estamos num mundo onde dinheiro, finanças, tudo roda rapidamente. Porque as pessoas não têm o mesmo direito de circular? Nós somos à favor, é claro, de uma cidadania universal. É claro, por exemplo, terrorista é terrorista, mas o imigrante não é terrorista, o refugiado não é terrorista, então vamos tratar de maneira diferente cada questão. Acho que estamos a favor dos seres humanos, dos direitos dos seres humanos. E muitas vezes isso é esquecido. Como Missão $\mathrm{Paz}$, a gente vai martelando. As causas migratórias atuais têm responsabilidades sociopolíticas de países, de potências, que estão fechando. Se a gente pensar os 
haitianos, o estrago que a França, os Estados Unidos fizeram no Haiti, eles têm uma dívida social que esquecemos. Então, eles teriam que ajudá-los. A migração não é tão natural. É natural, é verdade, mas tem causas históricas e dívidas históricas enormes de potências. Isso tem que ser lembrado sempre.

\section{Além do Brasil, outro país adotou uma política humanitária para com haitianos como o fez o Brasil?}

Pe. Parise: Acho que não. Mas não coloco a mão no fogo, no sentido que, pelo que eu vi até agora, não ouvi falar de outras políticas semelhantes.

\section{Qual é a motivação do trabalho de acolhimento de migrantes que a Missão Paz realiza?}

Pe. Parise: É interessante que a motivação, eu diria, no caso da estrutura, é uma motivação religiosa e humanitária, no caso de voluntários, todos os que atuam aqui, eu acho que é o ser humano. Porque temos pessoas que atuam aqui que são espíritas, pessoas que são evangélicas, temos uma budista, ateus. Mas elas colocam o ser humano como centro. Então, apesar da estrutura pertencer à igreja, inclusive eu também sou da Igreja Católica, mas isso não exclui, inclui todos os que colocam o imigrante, o que nos junta. $O$ imigrante não é uma ameaça, é um ser humano.

\section{Notas}

${ }^{1}$ A Missão Paz está localizada à Rua do Glicério, 225. Bairro Liberdade. São Paulo-SP. Nota do Editor.

${ }^{2}$ Bairro paulistano onde se localiza o ITESP - Instituto teológico de São Paulo, o Seminário João XXIII e o Orfanato Cristóvão Colombo, todos eles pertencentes à Congregação dos Padres Scalabrinianos. O Centro de Estudos Migratórios nasce no ITESP. Nota do Editor.

${ }^{3}$ Trata-se de um Projeto de nova Lei de migração para o Brasil, que pretende mudar o enfoque do atual Estatuto do Estrangeiro, centrado na "Segurança Nacional", para um tratamento aos migrantes e refugiados orientado pelos Direitos Universais da Pessoa Humana. Nota do Editor

${ }^{4}$ O Arsenal da Esperança nasceu em São Paulo no ano de 1996. Anteriormente, em seu lugar, funcionava a antiga Hospedaria de Imigrantes que, de fins do século XIX até a a década de 1970, recebeu milhares de imigrantes oriundos de diversos países. Hoje, o Arsenal da Esperança acolhe cerca de 1.200 pessoas em dificuldade, "povo em situação de rua", buscando oportunidades para recomeçar suas vidas. O Arsenal da Esperança é ligado ao SERMIG - Serviço Missionário Giovani, que nasceu em 1964, em Turim, Itália. Nota do Editor.

${ }^{5}$ O Padre Paolo Parise se refere ao conjunto arquitetônico da Missão Paz. Nota do Editor.

${ }^{6} \mathrm{O}$ Ministério da Justiça e o Ministério do Trabalho. Nota do Editor. 